\title{
Numerical Simulation of Gas-Solid Two-Phase Jet in a Non-pressure-accumulated and Handheld Fire Extinguisher
}

\author{
Yidan $\mathrm{Wu}^{1}$, Hongwei Zhuang ${ }^{2}$ and Pengfei $\mathrm{Yu}^{3}$ \\ ${ }^{1}$ Xinjiang Corps of the Armed Police Force, Engineering University of the Armed Police Force, Xi'an, China \\ ${ }^{2}$ College of Equipment Engineering, Engineering University of the Armed Police Force, Xi' an, China \\ ${ }^{3}$ Hainan Corps of the Armed Police Force, Haikou, China
}

\begin{abstract}
The ultra-fine dry powder injection process in non-pressure-accumulated and handheld fire extinguishers involves gas-phase and solid-phase two-phase movement. The fire-extinguishing effect is closely related to its jet form. In order to study the jet form accurately, this paper selects the discrete particle model, combines the advantages of Lagrange method and Euler method, and uses CFD simulation software FLUENT to numerically simulate the gas-solid two-phase jet shape of a nonpressure-accumulated and handheld fire extinguisher. And compares the simulation results with the experimental results, analyzes the flow field characteristics inside and outside the cylinder. The results show that the numerical simulation agrees well with the experimental results and can better represent the motion state of the two-phase flow. The numerical simulation results show that the duration of extinguishing agent particles injection is 1.07s, which is very close to the actual injection duration of $1.13 \mathrm{~s}$. The difference between the two is $4.4 \%$. Within the acceptable error range, it is further proved that the simulation results are good agreements with the experiment.
\end{abstract}

Keywords-non-pressure-accumulated; handheld extinguisher; gas-solid two-phase jet; numerical simulation

\section{INTRODUCTION}

The non-pressure-accumulated and handheld fire extinguisher (NHFE) utilizes the pyrotechnic aerosol gas generated by the combustion of the gas generating agent to stably and continuously spray the ultra-fine dry powder inside the cylinder to act on the flame-burning surface of the human body or other objects, through chemical inhibition and cutting off the combustion chain chemical and physical dilution effect it will stop burning and play a fire-extinguishing effect. The pyrotechnic (hot) aerosol gas produced during the combustion of the extinguisher is a continuous phase, and the ejected ultrafine powder is a discrete phase. Therefore, the extinguishing agent application process is a gas-solid twophase flow process. The characteristics of the flow field are the key factors that affect the fire extinguishing effect. As a result, numerical simulation and experimental research on the jet flow process of NHFE and in-depth analysis of the jet form have become an urgent issue.

At present, $\mathrm{H}$ Afshar et al. [1] analyze a new type of nanoparticles' heat transfer in gas-phase flow based on the Lagrangian coordinate, and uses the Maxwell model of the classical theory of viscous properties to track the motion of nanoparticles, found at a volume fraction of less than $1 \%$, the nanoparticles enhance the heat transfer capacity of the gas phase fluid. Williams et al. [2] used Computational Fluid Dynamics (CFD) software to simulate the flow characteristics of a gas-solid two-phase flow in a pneumatic conveyor belt. The Euler-Euler method was used to simulate the pressure gradient. The calculated results agree well with the measured data. According to the theory of gas-solid two-phase flow, Chen Junshi et al. [3] used a discrete-phase model to simulate the dust concentration in the broken copper chamber, which was in good agreement with the measured data. The related simulation analysis of the flow field characteristics of gassolid two-phase flow in NHFE has been less reported.

In order to study the performance of non-pressureaccumulated and handheld fire extinguisher and lay the foundation for functional and structural improvement. This paper uses the CFD simulation software FLUENT to simulate the gas-solid two-phase flow field characteristics of the nonpressure-accumulated and handheld fire extinguisher, and uses high-speed photography results to verify the simulation results.

\section{NUMERICAL SimUlation}

\section{A. Entity Model and Calculation Model}

\section{1) Solid model and grid division}

The gas-solid two-phase flow simulation of a non-pressureaccumulated and handheld fire extinguisher is mainly to simulate the injection of an ultrafine dry powder fire extinguishing agent. The entire process takes place in the cylinder, as shown in FIGURE. 1.

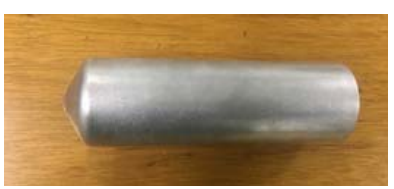

FIGURE I. NON-PRESSURE STORAGE HANDHELD FIRE EXTINGUISHER CYLINDER

The establishment of its geometric model needs a reasonable degree of simplification. According to the size of the body cavity, the main body of the geometric model is 
$162 \mathrm{~mm}$ long and $47 \mathrm{~mm}$ in diameter. The inner cone angle at the nozzle is $130^{\circ}$ and the nozzle diameter is $7 \mathrm{~mm}$. The gas generator structure is ignored and instead an air intake is set at the bottom of the model. It is known that there are 8 gas producing holes of $5 \mathrm{~mm}$ diameter in the gas generator, so the size of the inlet is approximately the sum of the size of 8 gas producing holes, and its diameter is $17 \mathrm{~mm}$. The more precise the mesh set, the higher accuracy of the calculation results and the longer the required computation time. In order to more accurately study the gas-solid two-phase flow of fire extinguisher, the maximum volume is about $8.5 \times 10^{-3} \mathrm{~m}^{3}$ and the minimum volume is about $6.3 \times 10^{-11} \mathrm{~m}^{3}$ when dividing the calculation area grid. The total number is about 380,000 . The cylinder model and mesh are shown in Figure 2.
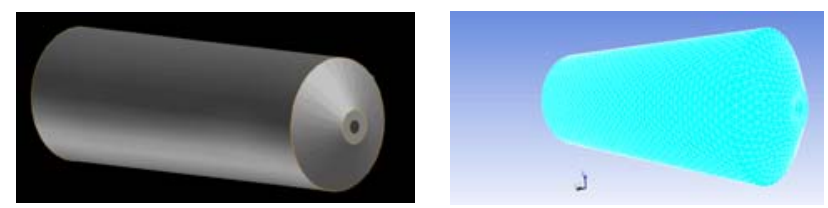

FIGURE II. BARREL MODEL AND MESH

Observed by experiment, the size of the flow field is set to $4 \mathrm{~m} \times 3 \mathrm{~m} \times 3 \mathrm{~m}$, and the direction of the fire extinguisher nozzle is horizontal. The geometric model of the gas-solid two-phase flow field in the entire NHFE has a complex shape, so the tetrahedral mesh is divided by the T-grid method, and a solid model is rapidly constructed. The entire calculation area model and flow field meshing are shown in Figure 3.
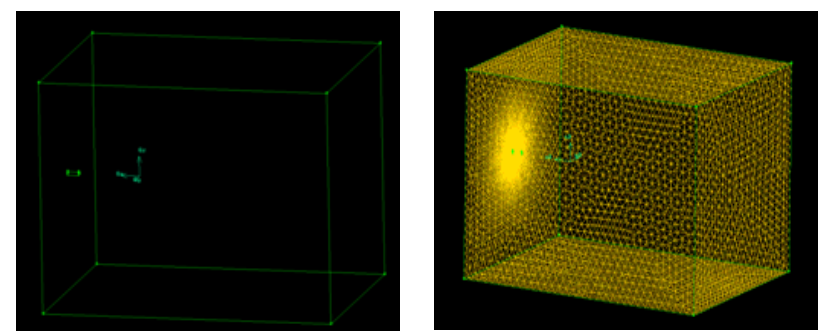

FIGURE III. COMPUTE AREA MODEL AND GRID DIVISION

\section{2) Physical model and state equaation}

According to the gas-solid two-phase flow characteristics of the NHFE to select the appropriate physical model is the basis for the mathematical description of the two-phase flow [4]. The discrete particle model considers the gas phase as a continuous phase and studies the fluid motion in Euler coordinates. For continuous fluids, the same local average Navier-Stokes equations as the continuous media model are used [5]. The solid particles are treated as discrete phases, and the trajectories of the particles are studied in the Lagrange coordinate. The gas-solid two-phase flow of NHFE is a dense gas-solid two-phase flow, that the force between particles and gas is not negligible. In the view of the inaccuracy of the description of the physical properties of particles by the continuous medium model and the difficulty of the application and calculation requirements of the fluid particle model, this paper selects the discrete particle model to study the gas-solid two-phase flow of NHFE. Its control equations are as follows:

(1) Gas-phase control equation. According to the law of conservation of mass and Newton's second law, the gas phase properties are described in Euler coordinates.

i. Gas-phase continuous equation:

$$
\frac{\partial \rho}{\partial \mathrm{t}}+\operatorname{div}(\rho \overrightarrow{\mathrm{u}})=0
$$

In the formula, $\rho$ is a constant stands for the gas phase density; $\vec{u}$ is a vector stands for gas phase velocity; the form of $\operatorname{div}(\mathrm{x})$ is $\operatorname{div}(\overrightarrow{\mathrm{a}})=\partial \mathrm{a}_{\mathrm{x}} / \partial \mathrm{x}+\partial \mathrm{a}_{\mathrm{y}} / \partial \mathrm{y}+\partial \mathrm{a}_{\mathrm{z}} / \partial \mathrm{z}$, which means divergence.

ii. Vapor-phase momentum equation:

$$
\begin{aligned}
& \frac{\partial(\rho \mathrm{u})}{\partial \mathrm{t}}+\operatorname{div}(\rho \mathrm{uu})=\operatorname{div}(\mu \operatorname{gradv})-\frac{\partial \mathrm{p}}{\partial \mathrm{t}}+\mathrm{S}_{\mathrm{u}} \\
& \frac{\partial(\rho \mathrm{v})}{\partial \mathrm{t}}+\operatorname{div}(\rho \mathrm{v} \overrightarrow{\mathrm{u}})=\operatorname{div}(\mu \operatorname{gradv})-\frac{\partial \mathrm{p}}{\partial \mathrm{t}}+\mathrm{S}_{\mathrm{v}} \\
& \frac{\partial(\rho \mathrm{w})}{\partial \mathrm{t}}+\operatorname{div}(\rho \mathrm{w} \overrightarrow{\mathrm{u}})=\operatorname{div}(\mu \operatorname{gradv})-\frac{\partial \mathrm{p}}{\partial \mathrm{t}}+\mathrm{S}_{\mathrm{w}}
\end{aligned}
$$

In the formula, The form of $\operatorname{grad}(\mathrm{x})$ is $\operatorname{grad}()=\partial() / \mathrm{x}+\partial() / \mathrm{y}+\partial() / \mathrm{z}, \quad \mathrm{u}, \mathrm{v}, \quad \mathrm{w}$ are the components of the velocity vector in $x, y, z$, Symbols $S_{u}, S_{v}$ and $S_{w}$ are generalized source terms for momentum conservation equations.

(2) Solid phase control equation

\section{i. Particle motion equation}

The movement of extinguishing agent particles in the flow field can be divided into translational motion and rotational motion, and non-uniform motion. In order to describe the movement state of the extinguishing agent particles more accurately, the non-uniform motion of the entire extinguishing agent particles is regarded as an infinite number of uniform motions. That is, using the concept of differentiation, the extinguishing agent particles are considered as uniform motion at each very small time interval. Available, the translational and rotational equations of extinguishing agent particles in three-dimensional coordinates:

$$
\begin{gathered}
\mathrm{m} \frac{\partial^{2} \mathrm{~S}_{\mathrm{x}}}{\partial \mathrm{t}^{2}}=\left(\mathrm{f}_{\mathrm{Cx}}+\mathrm{f}_{\mathrm{Fx}}-\mathrm{V}_{\mathrm{p}} \nabla \mathrm{P}_{\mathrm{x}}\right)+\mathrm{mg}_{\mathrm{x}} \\
\mathrm{m} \frac{\partial^{2} \mathrm{~S}_{\mathrm{y}}}{\partial \mathrm{t}^{2}}=\left(\mathrm{f}_{\mathrm{Cy}}+\mathrm{f}_{\mathrm{Fy}}-\mathrm{V}_{\mathrm{p}} \nabla \mathrm{P}_{\mathrm{y}}\right)+\mathrm{mg}_{\mathrm{y}} \\
\mathrm{m} \frac{\partial^{2} \mathrm{~S}_{\mathrm{z}}}{\partial \mathrm{t}^{2}}=\left(\mathrm{f}_{\mathrm{Cz}}+\mathrm{f}_{\mathrm{Fz}}-\mathrm{V}_{\mathrm{p}} \nabla \mathrm{P}_{\mathrm{z}}\right)+\mathrm{mg}_{\mathrm{z}}
\end{gathered}
$$




$$
\begin{gathered}
\frac{\partial \omega_{\mathrm{P}_{x}}}{\partial \mathrm{t}}=\frac{T_{\mathrm{P}_{\mathrm{x}}}}{\mathrm{I}} \\
\frac{\partial \omega_{\mathrm{P}_{\mathrm{y}}}}{\partial \mathrm{t}}=\frac{\mathrm{T}_{\mathrm{P}_{\mathrm{y}}}}{\mathrm{I}} \\
\frac{\partial \omega_{\mathrm{P}_{z}}}{\partial \mathrm{t}}=\frac{\mathrm{T}_{\mathrm{P}_{z}}}{\mathrm{I}} \\
\mathrm{f}_{\mathrm{F}}=\mathrm{f}_{\mathrm{D}}+\mathrm{f}_{\mathrm{LM}}+\mathrm{f}_{\mathrm{am}}+\mathrm{f}_{\mathrm{ht}}+\mathrm{f}_{\mathrm{ot}}
\end{gathered}
$$

In the formula, $\mathrm{S}$ stands for the particle displacement of the extinguishing agent; $f_{C}$ stands for the collision force of the extinguishing agent particles; $\mathrm{f}_{\mathrm{F}}$ stands for the total force of the gas on the extinguishing agent particles; $\nabla \mathrm{P}$ stands for the pressure gradient of the flow field; $V_{p}$ stands for the volume of the individual extinguishing agent particles; $\overrightarrow{\omega_{\mathrm{p}}}$ stands for the angular velocity of the extinguishing agent particles rotation; $T_{P}$ stands for the rotational moment of resultant force of the extinguishing agent particles; I stands for the rotational inertia of the extinguishing agent particles. After $\Delta t$ that represents the time interval, the position of the extinguishing agent particles is:

$$
\begin{array}{r}
\mathrm{S}_{\mathrm{x}}=\mathrm{S}_{\mathrm{x} 0}+\mathrm{V}_{\mathrm{x}} \Delta \mathrm{t} \\
\mathrm{S}_{\mathrm{y}}=\mathrm{S}_{\mathrm{y} 0}+\mathrm{V}_{\mathrm{y}} \Delta \mathrm{t} \\
\mathrm{S}_{\mathrm{z}}=\mathrm{S}_{\mathrm{z} 0}+\mathrm{V}_{\mathrm{z}} \Delta \mathrm{t}
\end{array}
$$

The line speed of extinguishing agent particles is:

$$
\begin{aligned}
& \mathrm{V}_{\mathrm{x}}=\mathrm{V}_{\mathrm{x} 0}+\dot{\mathrm{V}}_{\mathrm{x}} \Delta \mathrm{t} \\
& \mathrm{V}_{\mathrm{y}}=\mathrm{V}_{\mathrm{y} 0}+\dot{\mathrm{V}}_{\mathrm{y}} \Delta \mathrm{t} \\
& \mathrm{V}_{\mathrm{z}}=\mathrm{V}_{\mathrm{z} 0}+\dot{\mathrm{V}}_{\mathrm{z}} \Delta \mathrm{t}
\end{aligned}
$$

The angular velocity of the extinguishing agent particles is:

$$
\begin{aligned}
& \omega_{\mathrm{P}_{\mathrm{x}}}=\omega_{\mathrm{P}_{\mathrm{x} 0}}+\omega_{\mathrm{P}_{\mathrm{x}}} \Delta \mathrm{t} \\
& \omega_{\mathrm{P}_{\mathrm{y}}}=\omega_{\mathrm{P}_{\mathrm{y} 0}}+\omega_{\mathrm{P}_{\mathrm{y}}} \Delta \mathrm{t}
\end{aligned}
$$

$$
\omega_{\mathrm{P}_{\mathrm{z}}}=\omega_{\mathrm{P}_{\mathrm{z} 0}}+\omega_{\mathrm{P}_{\mathrm{z}}} \Delta \mathrm{t}
$$

\section{ii. Collisions between particles}

In the dense gas-solid two-phase flow, the impact of collisions between particles is quite prominent [6], and plays an important role in the redistribution of particle momentum [7], and it also has a great influence on the flow of gas phase. Collisions between particles are divided into two types, central collision and eccentric collision.

The central collision refers to the fact that when the particles collide, their geometric center velocity vectors are exactly on the same line. If two spherical particles form a central collision, a generator deforms at the point of impact and a resistance is generated. The magnitude of this force is proportional to the displacement and stiffness of the material.

Eccentric collisions are collisions that if two spherical particles form an eccentric collision, the contact force at the collision point can be decomposed into a normal component force and a tangential component force, which are calculated from the normal and tangential deformation displacement and kinetic energy loss, respectively.

Mark the particle $\mathrm{i}$ and particle $\mathrm{j}$, when the two collide, the force acting on the particles can be calculated by the following equations, in which the normal component force:

$$
\overrightarrow{f_{\text {Cnij }}}=\left(-k_{n} \delta_{\text {nij }}-\eta_{n} \overrightarrow{V_{\text {rij }}} \overrightarrow{n_{i j}}\right) \overrightarrow{n_{i j}}
$$

Tangential force:

$$
\overrightarrow{\mathrm{f}_{\mathrm{Ctij}}}=-\mathrm{k}_{\mathrm{t}} \delta_{\mathrm{tij}}-\eta_{\mathrm{t}} \overrightarrow{\mathrm{V}_{\mathrm{sij}}}
$$

In the formula, $\delta_{\mathrm{nij}}, \delta_{\mathrm{tij}}$ are respectively the particles normal and tangential variables, $\mathrm{k}_{\mathrm{n}}, \mathrm{k}_{\mathrm{t}}$ are the normal elastic coefficient and tangential elasticity coefficient respectively, $\eta_{\mathrm{n}}, \eta_{\mathrm{t}}$ are the normal damping coefficient and the tangential damping coefficient, respectively [8]:

$$
\eta_{\mathrm{n}}=\eta_{\mathrm{t}}=-2 \ln \mathrm{e} \sqrt{\frac{\mathrm{m}_{\mathrm{p}} \mathrm{k}_{\mathrm{n}}}{\pi^{2}+\ln ^{2} \mathrm{e}}}
$$

In the formula, e stands for the coefficient of recovery, choose $0.9 . \overrightarrow{\mathrm{V}_{\mathrm{sij}}}$ stands for the slip speed for the contact point, calculated by following formula:

$$
\overrightarrow{\mathrm{V}_{\mathrm{ijj}}}=\overrightarrow{\mathrm{V}_{\mathrm{rij}}}-\left(\overrightarrow{\mathrm{V}_{\mathrm{rij}}} \cdot \overrightarrow{\mathrm{n}}\right) \overrightarrow{\mathrm{n}}+\frac{\mathrm{dp}}{2}\left(\overrightarrow{\omega_{\mathrm{i}}}-\overrightarrow{\omega_{\mathrm{j}}}\right) \overrightarrow{\mathrm{n}}
$$

If satisfied $\left|\overrightarrow{\mathrm{f}_{\text {Ctij }}}\right|>\mu_{\mathrm{f}} \overrightarrow{\mathrm{f}_{\text {Cnij }}}$, the tangential force of the particles $\mathbf{i}$ is determined by the following formula: 


$$
\overrightarrow{\mathrm{f}_{\mathrm{Ctij}}}=-\mu_{\mathrm{f}} \overrightarrow{\mathrm{f}_{\mathrm{Cnij}}} \mathrm{t}_{\mathrm{ij}}
$$

In the above formula $\overrightarrow{t_{i j}}$ is a unit vector, determined by the following formula:

$$
\overrightarrow{\mathrm{t}_{\mathrm{ij}}}=\overrightarrow{\mathrm{V}_{\mathrm{sij}}} /\left|\overrightarrow{\mathrm{V}_{\mathrm{sij}}}\right|
$$

Tangential deformation $\overrightarrow{\delta_{\text {tij }}}$ is determined by the following formula:

$$
\overrightarrow{\delta_{\text {tij }}}=\overrightarrow{\mathrm{f}_{\text {Cnij }}} / \mathrm{k}_{\mathrm{t}}
$$

When multiple particles colliding with particles $i$, the resultant force and moment acting on the particles $\mathrm{i}$ are:

$$
\begin{gathered}
\overrightarrow{\mathrm{f}_{\mathrm{Ci}}}=\sum_{\mathrm{j}}\left(\overrightarrow{\mathrm{f}_{\text {Cnij }}}+\overrightarrow{\mathrm{f}_{\text {Ctij }}}\right) \\
\overrightarrow{\mathrm{T}_{\mathrm{Ci}}}=\sum_{\mathrm{j}}\left(\overrightarrow{\mathrm{r}_{\mathrm{s}}} \overrightarrow{\mathrm{n}_{\mathrm{ij}}} \times \overrightarrow{\mathrm{f}_{\mathrm{Ctij}}}\right)
\end{gathered}
$$

When the particles collide with the wall, only the particles $\mathrm{j}$ need to replace the wall. Let the other calculations are the same as the calculation of the collision between particles.

\section{B. Calculation Methods and Conditions}

\section{1) Calculation method}

The simulation of fire extinguishing agent being ejected from the fire extinguisher body is divided into in two steps: the first is to perform steady-state simulation to obtain the airflow field; the second is to add a discrete phase to the airflow field that has been obtained to simulate tracking the trajectory of discrete phase particles.

In the steady-state simulation calculation, the standard k- $\varepsilon$ turbulence model is adopted, and the wall surface flow also adopts the standard wall surface equation. Specific gas composition and speed are given at the gas inlet, that the gas composition is given in "Species" according to "12.1\% $\mathrm{K}_{2} \mathrm{O}$, $26.6 \% \mathrm{~N}_{2}, 24.7 \% \mathrm{H}_{2} \mathrm{O}, 25.2 \% \mathrm{CO}, 2.7 \% \mathrm{CO}_{2} "$ and the speed is given by $11.5 \mathrm{~m} / \mathrm{s}$ at which the extinguishing agent particles can be completely blown from the fire extinguisher cylinder at around $1.13 \mathrm{~s}$. At the initial stage, the fire extinguisher cylinder and the calculation area are all air. When the boundary conditions are set, the ground of the calculation area is set as "wall"; the other surfaces of the calculation area are set to a pressure exit of 0 , a free opening to simulate the air boundary; the fire extinguisher cylinder is set as a solid "wall". Relaxation factors are: 0.3 for pressure, 0.7 for momentum, others remain the default size.

After the steady state simulation converges, a discrete phase is added for transient simulation. The discrete phase is added as "Injections", the surface jet source was selected, and the entire extinguisher body was selected as the jet source. The initial velocity of extinguishing agent particles is 0 , the average diameter size is $15 \mu \mathrm{m}$, and the total mass is $150 \mathrm{~g}$. Particle tracking selects a discrete random float model. The "Spherical" model was selected for force model. Due to the extinguishing agent particles were lighter and would be subjected to the buoyancy of the air, and there would be collisions between particles that make device collisions considered in simulations, "Saffman Lift Force" and DEM model were used for the physical model of the discrete phase. In addition, the gravity item is open, the acceleration is set to $9.81 \mathrm{~m} / \mathrm{s}^{2}$, and the direction is vertical downward. The time step of transient simulation is $0.01 \mathrm{~s}$, which means the particle is traced once every $0.01 \mathrm{~s}$ to obtain the trajectory and speed.

\section{2) Solution Control}

It is known the fire extinguisher injection duration is approximate $1.13 \mathrm{~s}$. Combined with its injection distance, it can be seen that the two-phase flow state is a low-speed flow. The simulation uses a pressure-based solver. In the solution control, the "SIMPLE" algorithm is used for the coupling of pressure and velocity. Spatial Discrete Method: The gradient is "Least Squares Cell Based", choose the "Standard" pressure, the momentum uses second-order windward dispersion, and the others adopt first-order windward dispersion.

\section{3) Physical Parameters}

Physical parameters of solid particles and gaseous media directly affect the results of the gas-solid two-phase flow simulation of NHFE [9]. The solid particles in NHFE are ultra-fine dry powder fire extinguishing agents, and the gaseous medium is a pyrotechnic hot aerosol generated by the combustion reaction of the gas generating agent. Among them, the formulation of the gas generating agent is based on the mass fraction of $72 \% \mathrm{KNO}_{3}, 18 \% \mathrm{C}_{3} \mathrm{H}_{6} \mathrm{~N}_{6}$, and $10 \% \mathrm{C}_{13} \mathrm{H}_{12} \mathrm{O}_{2}$, according to the chemical reaction formula:

$2 \mathrm{KNO}_{3}+0.4 \mathrm{C}_{3} \mathrm{H}_{6} \mathrm{~N}_{6}+0.14 \mathrm{C}_{13} \mathrm{H}_{12} \mathrm{O}_{2} \stackrel{\text { burn }}{\longrightarrow} \mathrm{K}_{2} \mathrm{O}+2.2 \mathrm{~N}_{2}+2.04 \mathrm{H}_{2} \mathrm{O}+2.80 \mathrm{CO}+0.22 \mathrm{CO}_{2}$

The composition of the gaseous medium can be $12.1 \%$ $\mathrm{K}_{2} \mathrm{O}, 26.6 \% \mathrm{~N}_{2}, 24.7 \% \mathrm{H}_{2} \mathrm{O}, 25.2 \% \mathrm{CO}, 2.7 \% \mathrm{CO}_{2}$. The physical characteristics of gas-solid two phases are shown in Table 1.

TABLE I. PHYSICAL CHARACTERISTICS OF GAS-SOLID TWOPHASE

\begin{tabular}{|l|l|}
\hline Solid Phase & $\begin{array}{c}\text { Ultrafine dry powder fire } \\
\text { extinguishing agent }\end{array}$ \\
\hline The average particle size $/ \mu \mathrm{m}$ & 15 \\
\hline Particle density $/\left(\mathrm{kg} / \mathrm{m}^{3}\right)$ & 800 \\
\hline Gas phase & $\mathrm{K}_{2} \mathrm{O} 、 \mathrm{~N}_{2} 、 \mathrm{H}_{2} \mathrm{O}$ Mixed gas etc. \\
\hline Molar mass $/(\mathrm{g} / \mathrm{mol})$ & 31.75 \\
\hline density $/\left(\mathrm{kg} / \mathrm{m}^{3}\right)$ & 1.42 \\
\hline
\end{tabular}

\section{Calculation Results AnAlysis And Discussion}

\section{A. Jet Characteristics Analysis}

The left side of FIGURE. 4 shows the simulation results of the fire extinguishing agent in NHFE at different times, and the 
right side shows the actual injection state of the corresponding time taken by the high-speed camera.

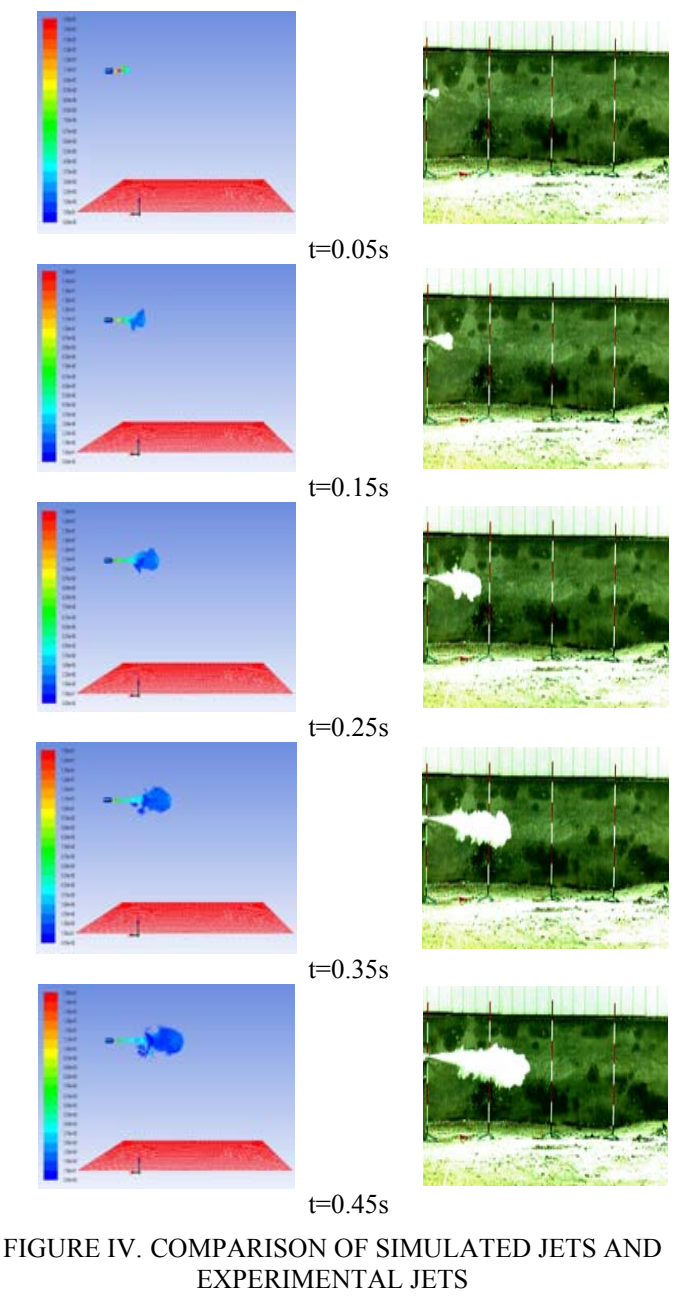

After the NHFE is started, the gas generator reacts to generate hot aerosol gas and feeds it into the cylinder. The gas accumulates and generates pressure. When the pressure breaks through the pressure value that the nozzle membrane can withstand, the gas entrain and spray out with ultra-fine dry powder fire extinguishing agent. As shown in FIGURE. 4, since the gas powder flow is a low-speed flow, the "bundle jet" stage in the high-pressure gas-solid two-phase injection cannot be observed. Under the effect of external atmospheric resistance and internal airflow, turbulent motion occurs at the boundary of the extinguishing agent jets flow, making the boundary becomes unstable and forms "plumb phenomenon"--gas-powder two-phase fluid undergoes momentum exchange with air, movement speed is slowed, and the fluid shape gradually expands to form a feather-like appearance. When the extinguishing agent powder momentum becomes smaller and smaller, until exhausted, particles at the front of the jet continue to diffuse forward mainly carried by the air, under the subsequent push of the gas-powder two-phase flow and particle molecular movement. At the same time, Figure. 4 shows that the comparison of simulated jet flow results and the experimental jet flow results are relatively consistent with each other.

\section{B. The Characteristics of the Flow Field Inside and Outside the Cylinder}

Figure 5 shows the distribution of the gas velocity of the power source in the cylinder in the vertical section.

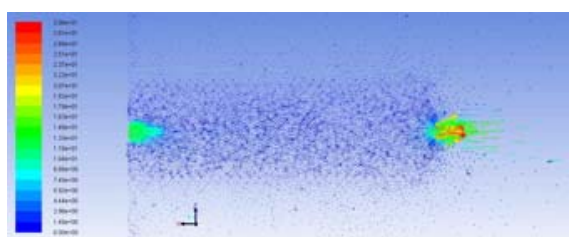

FIGURE V. CYLINDRICAL VERTICAL SECTION ON GAS VELOCITY VECTOR

From FIGURE. 5, it can be seen that after the power source gas enters the cartridge, it is mixed with the ultrafine dry powder fire extinguishing agent particles and flows between the fire extinguishing agent particles, giving the fire extinguishing agent particles a certain amount of momentum. The movement of the gas-solid two-phase flow on the central axis is the most intense and it moves generally toward the nozzle. In addition, the rebounding of the flow collided on the wall surface of the cylinder exacerbate the collision between the particles, and a more disorderly state was formed in the local area, destroying the trajectory of the two-phase flow toward the nozzle. field.

Figure 6 shows the distribution of gas velocity in the flow

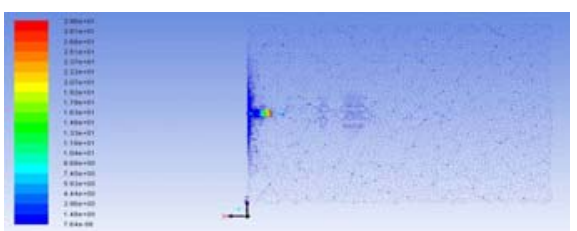

FIGURE VI. GAS VELOCITY IN A FLOW FIELD

As shown in Figure. 6, the fire extinguishing agent powder diffuses in the air after the ejection from the spout by gas envelop. When it is diffused to the maximum state, the original momentum of the gas is dissipated and the molecular heat movement begins.

Figure 7 shows the distribution flow of extinguishing agent particle velocity in the flow field.

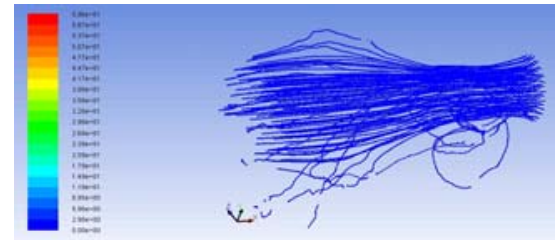

FIGURE VII. FIREFIGHTING AGENT PARTICLE VELOCITY STREAMLINE DIAGRAM

As shown in FIGURE. 7, the extinguishing agent particles are very strong in the center of the jet during the spraying 
process. This is not conducive to the spread of ultra-fine dry powder fire extinguishing agent, and cannot cover enough area, making the fire extinguishing agent too concentrate in a small area, which reduces the concentration of extinguishing agent particles in other areas so as to fail to achieve the expected fire extinguishing performance.

During the entire simulation process, the spray duration of the extinguishing agent particles was $1.07 \mathrm{~s}$, which was very close to the actual injection duration of $1.13 \mathrm{~s}$. The difference between the two was $4.4 \%$ that within the acceptable error range. This also further proved that the simulation results are in good agreement with the experiment.

\section{CONCLUSION}

In this paper, the FLUNET software is used to simulate the gas-solid two-phase jet motion of a non-pressure-accumulated and handheld fire extinguisher, and the following conclusions are drawn:

(1) The comparison results show that the numerical simulation results are in good agreement with the experiment results. Using simulation instead of the experimental research can provide new research methods and ideas for the next research.

(2) For the study of gas-solid two-phase jets, the discrete particle model can effectively track the particle trajectory, depict the role of particles and gas, and can better predict the particle diffusion.

(3) In the whole simulation process, the spray duration of the extinguishing agent particles was $1.07 \mathrm{~s}$, which was very close to the actual injection duration 1.13s. The difference between the two was $4.4 \%$ that within the acceptable error range, further proving good consistency between the simulation results and experiments.

\section{REFERENCES}

[1] Afshar H, Shams M, Nainian SMM, Ahmadi G, Two-Phase Study of Fluid Flow and Heat Transfer in Gas-Solid Flows (Nanofluids)[J]. Applied Mechanics and Materials, 2012, (110-116): 3878-3882.

[2] Williams KC, Ma A, Zhou J, Jones MJ, Experimental and Numerical Research on Pressure Gradient of a Pneumatic Conveying Pipeline of Flyash[C]. Intelligent System Design and Engineering Application (ISDEA), 2012:1247-1250.

[3] Chen Yishi, Jiang Zhongan, Yang Bin, Wang Jingjing, Wang Wei. Numerical simulation of spatial distribution of dust concentration in the broken chamber[J]. Journal of China Coal Society, 2012, 11:1865-1870

[4] Vojir DJ, Michaelides EE, Effect of the history term on the motion of rigid spheres in a viscous fluid[J]. International Journal of Multiphase Flow, 1994, 20(3): 547-556.

[5] Fan Jinbiao. Numerical simulation of gas-solid two-phase flow in spouted bed[D]. Xi'an University of Architecture and Technology, 2006.

[6] Sommerfeld M., Modelling of particle-wall collisions in confined gasparticle flows[J]. Multiphase Flow, 1992, 18(6): 905-926.

[7] Elghobashi S., On Predicting Particle-Laden Turbulent Flow[J], Ajpplied Scientific Research, 1994, 52: 309-329.

[8] Shinichi Y, Toshihiko U, Yuuki J, Numerical simulation of air and particle motions in bubbling fluidized bed of small particles[J]. Powder Tech, 2000, 110: 158-168.

[9] Fan Chunqiao. Temperature field simulation and life assessment of $10 \mathrm{kV}$ dry-type transformers[D]. North China Electric Power University, 